\title{
New method for dynamic tribological test of engineering polymers
}

\author{
Á. SARANKó, R. KERESZTES, G. KALÁCSKA \\ Szent István University, Faculty of Mechanical Engineering Technology, saranko.adam@gmail.com \\ Szent István University, Faculty of Mechanical Engineering Technology, Department of Maintenance Engineering, \\ keresztes.robert@gek.szie.hu \\ Szent István University, Faculty of Mechanical Engineering Technology, kalacska.gabor@gek.szie.hu
}

Abstract: In this article, tribological tests of Polyamide 6 (PA 6), Ultra High Molecular Weight Polyethylene (UHMW $P E)$ and Polyoxymethylene copolymer (POM C) by a new testing method is introduced. The tribometer used in the test is capable for pin-on-disc measuring within all possible layout known in tribology practice, otherwise can be modified into special model of fatigue sliding test. The pin was a specimen made from examined materials, always in contact with a rotating metal disc under a normal load, which is usually static. However, since vibration exists in every practical scene as an important phenomenon, for instance in turning process, we added vibration load into the test. The supplement load is generated by a special-designed vibrating machine. Then properties of examined materials can be studied more profoundly under vibration load. As a result, different value of friction coefficient in static and vibration load have been discovered and taken into comparison.

\section{Introduction}

Friction phenomena usually encountered in daily life. It often has negative effect, but in specific cases it is useful, as without friction cars would not be able to turn. Tribology is the science of friction, wear and lubrication, which is as old as the human race even when it was not considered as an important area.

Many tests have been done in order to study tribology. One of the most favourite is the pin-on-disc test. The pin made from measured workpiece is placed in contact with a rotating disc under a normal load. The induced friction forces are measured with measuring sensors, from that the friction coefficient, which depends on the normal force, can be calculated. Another sensor measured the decreasing height between the pin end and the disc, which equals to the wear value. Then wear properties of examined materials can be described in details. The ambient temperature or the disc rotation speed can be measured with another sensor.

The normal load is often a weight load, which generates perpendicular force pushes the pin to the disc surface during the test. However, more realistic conditions need to be added, in order to study more profoundly the wear and friction phenomena exhibited in engineering practice, for instance in turning. During turning process, unignorable vibrations due to the eccentricity of rotating masses. My current research is elaborating a mathematical model describing the pin-on-disc measuring system, which is 
complemented by a vibration load. Hence, testing environment which has better approach to reality can be built.

\section{Methods}

The measurement system was described in details in a previous article ("Developed polymer pin-ondisc test system for fatigue-sliding models.")

Cylindrical polymer specimens, the "pin", which are $18 \mathrm{~mm}$ in length, $8 \mathrm{~mm}$ in diameter were used. They were Polyamide 6 (PA 6), Ultra High Molecular Weight Polyethylene (UHMW PE) and Polyoxymethylene copolymer (POM C). These materials can be manufactured with high tolerance, which significantly increases the accuracy for tribology tests. The "disc" material was general-purpose carbon steel S355, with a grounded surface. The average roughness $\left(R_{a}\right)$ was $0,12-0,15 \mu \mathrm{m}$. Tests were performed under pure adhesion conditions. Peripheral sliding speed was calculated from the radius of pin route and the disc revolution, what were measured by sensors and continuously monitored by computer. During the test, friction forces were examined. Strain gauges on force sensors and Spider8 amplifier were connected by wire to converting the analogue signals to digital, which are then transmitted to the computer. The chart-like visualization of the digital signals was achieved thanks to Catman software. The measuring frequency was $5 \mathrm{~Hz}$ during the measurements. Table 1 shows the parameters of the tests.

\begin{tabular}{|l|c|c|}
\hline & Static load test & Vibration load test \\
\hline Sliding speed $[\mathrm{m} / \mathrm{s}]$ & 0,8 & 0,8 \\
\hline Period of tests $[\mathrm{h}]$ & 0,5 & 0,5 \\
\hline Load $[\mathrm{N}]$ & 20,5 & $20,5 \pm 7$ \\
\hline Friction radius $[\mathrm{mm}]$ & 42,5 & 32,5 \\
\hline Disc surface roughness $[\mu \mathrm{m}]$ & Ra 0,12-0,15 & Ra 0,12-0,15 \\
\hline Ambient temperature $\left[{ }^{\circ} \mathrm{C}\right]$ & 23 & 23 \\
\hline
\end{tabular}

The static load is purely weight load of the pin-clamp-unit including the weight of the vibration machine, while the vibration load is generated by the operation of that machine. The measurements were done with a fluctuated $7 \mathrm{~N}$ vibration load added to $20,5 \mathrm{~N}$ static load. The frequency of vibration was $26 \mathrm{~Hz}$.

Before every test, the contact surface of the pin and disc were cleaned with methylated spirit. After one pair of static load and vibration load tests, the disc was grounded with fine sandpaper (P 500), and then the surface roughness was measured.

During the test, real-time data was tracked and diagram was drawn simultaneously on the computer screen. After completing, all data were saved for later processing, using a spreadsheet. 


\section{Results}

Diagrams were used to illustrate the results. Wear was measured during the tests, however, the pin route length is not sufficient long to analyse the wear of the polymers.

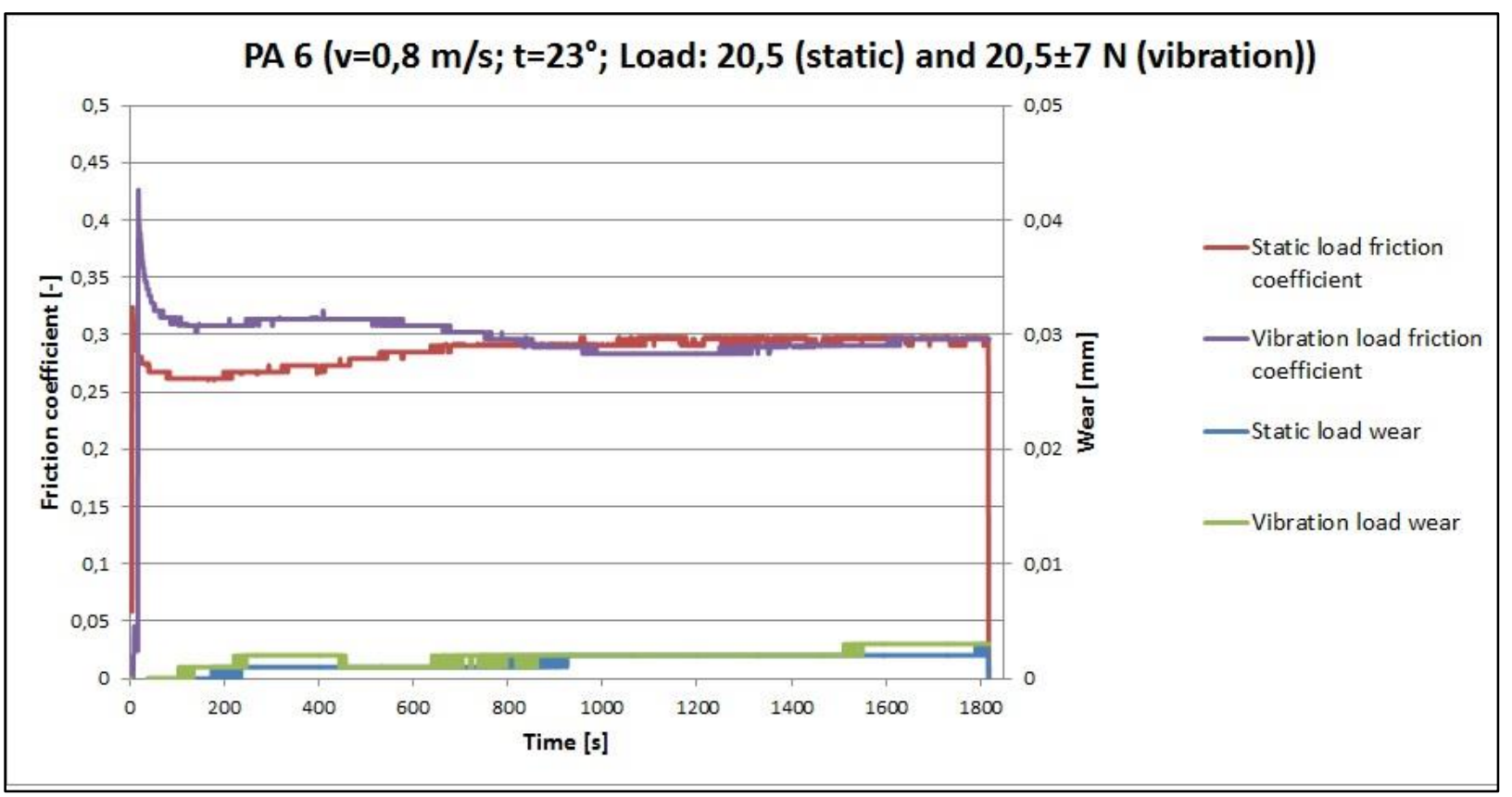

Figure 1. Results in case of PA 6.

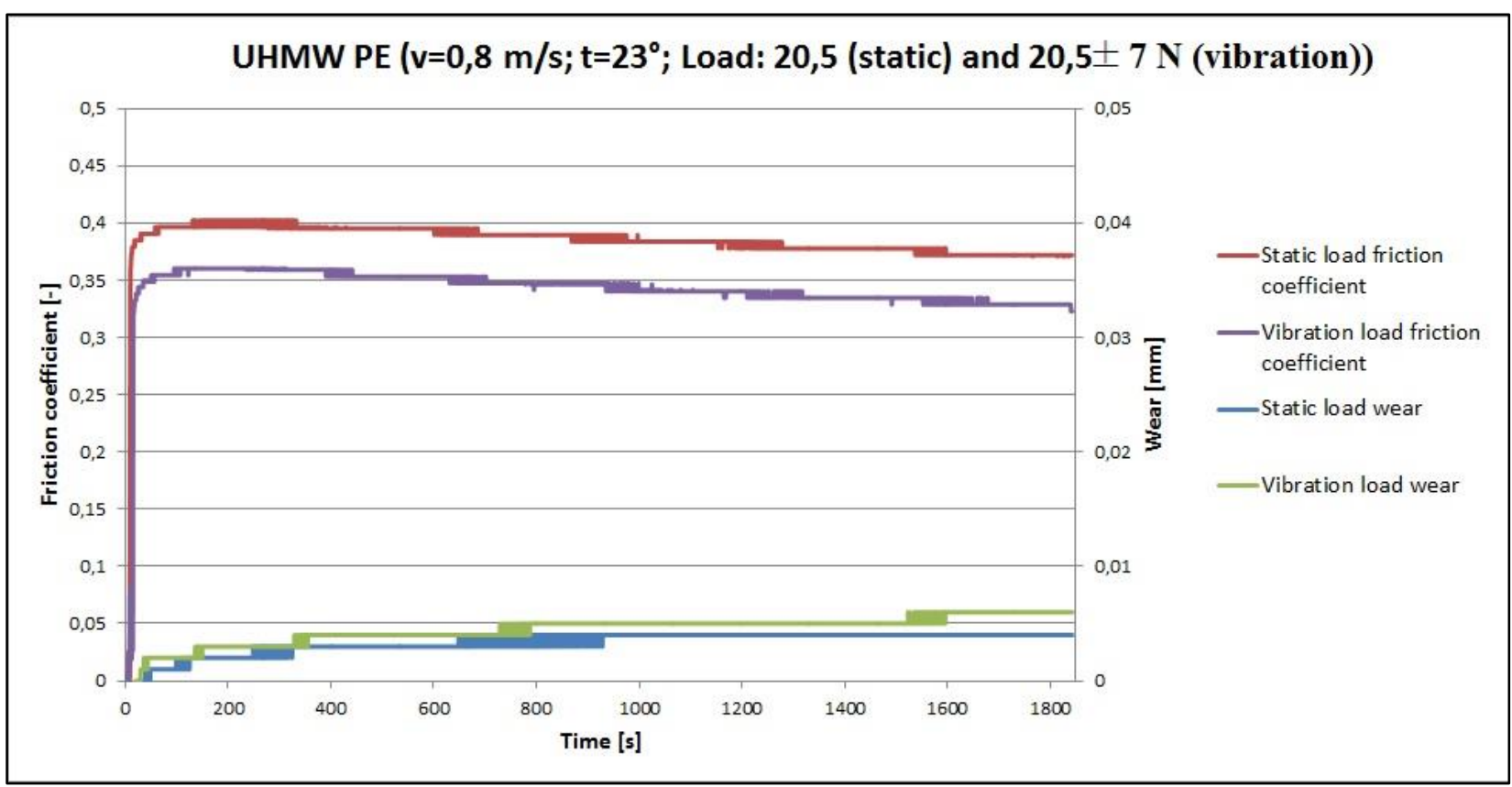

Figure 2. Results in case of UHMW PE.

The first figure shows the result of PA 6 under both test conditions. At the beginning of the test, both of the friction coefficients were reached a maximum value. During running-in period, the friction 
coefficients were varied differently: The vibration load friction coefficient was higher. After 15 minutes, both friction coefficient lines became stable and did not shows any significant changes.

In fig. 2 from the result of UHMW PE, the static friction coefficient was higher than the other one, but interestingly two friction coefficient lines were parallel.

In the third figure of POM C, a significant difference between the static and vibration load friction coefficient can be observed. It is a reversal phenomenon to two abovementioned tests: the friction coefficient in vibration load was higher than in static load, whose the value was nearly constant.

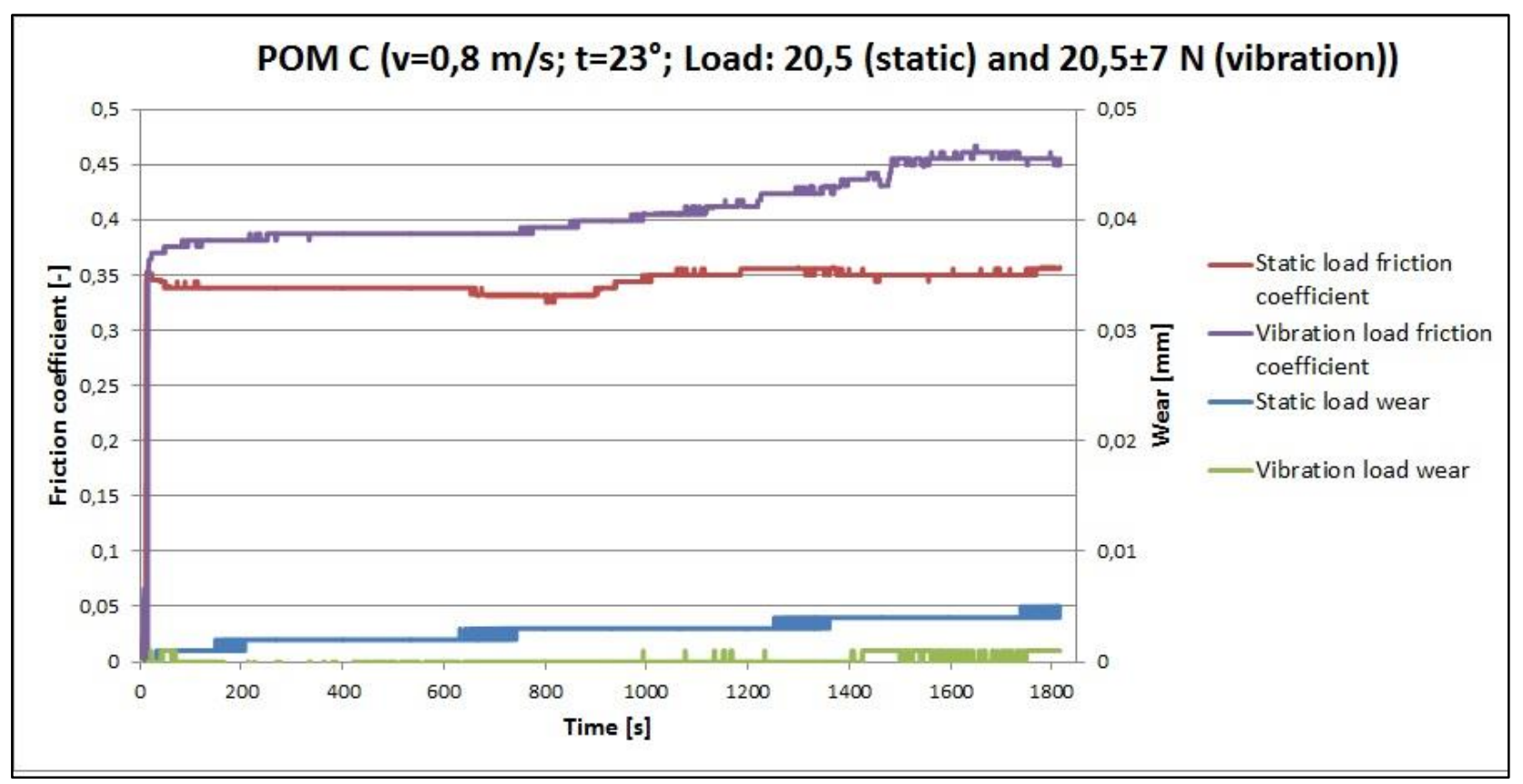

Figure 3. Results in case of POM C.

\section{Conclusions}

In all cases, wear phenomena were negligible with small values. Longer test distance is needed to consider the rationale further. Some conclusion can be point out:

- In case of static load, UHME PE had a higher friction coefficient value than in vibration load case, but during the test, it decreased.

- In case of static load, friction coefficient of POM C was nearly constant. After a short running-in period, friction coefficient of PA 6 also reached a constant value but in lower value.

- When the vibration load added, in case of PA 6, friction coefficient was high first, but then reached a constant value, which was nearly equal to the constant value in case of static load.

- Vibration load friction coefficient of UHMW PE was always lower during the test, with a nearly constant value of 0,04 .

- In case of POM C, the vibration load friction coefficient was higher and continuously increasing.

In future work, our research team is going to make more tests in this topic, with other different materials and test conditions. 


\section{References}

[1] M. H. Cho, S. Park (2011), Micro CNC surface texturing on polyoxymethylene (POM) and its tribological performance in lubricated sliding, Tribology International, 44, 859-867.

[2] R. Keresztes, G. Kalácska (2008), Polimer/acél fogaskerekek súrlódása, Műanyag és gumi, 45/6., 236-241.

[3] Á. Sarankó, G. Kalácska, R. Keresztes (2017), Developed polymer pin-on-disc test system for fatigue-sliding models, International Multidisciplinary Conference, 12th Edition. pp. 83-86.

[4] H. Unal, A. Mimaroglu, U. Kadioglu, H. Ekiz (2004), Sliding friction and wear behavior of polytetrafluoroethylene and its composites under dry conditions, Materials and Design 25, 239-245.

[5] D. Xiong, S. Ge (2001), Friction and wear properties of UHMWPE/Al2O3 ceramic under different lubricating conditions, Wear, 250, 242-245.

[6] E. S. Yoon, H. Kong, O. K. Kwon, J. E. Oh (1997), Evaluation of frictional characteristic for a pin-on-disk apparatus with different dynamic parameters, Wear, 203-204, 341-369. 